\title{
An atrionodal and nodo-Hisian gap phenomenon
}

\author{
T. Pop, D. Fleischmann, J. M. T. de Bakker, and S. Effert
}

From the First Medical Division and Helmholtz Institute for Biomedical Engineering, Rheinisch Westfälische Technische Hochschule, Aachen, West Germany

Two cases of the gap phenomenon are presented. The first was an example of a gap between the atrium and the $A V$ node. In the second the gap was at the nodo-Hisian junction. At a critical $\mathrm{H}_{1} \mathrm{H}_{2}$ interval splitting of the premature His potential occurred. A decrease of the $\mathrm{H}_{1} \mathrm{H}_{2}$ interval led to the disappearance of the distal $\mathrm{H}_{2}$ potential and to atrioventricular block. But at even shorter coupling intervals the $\mathrm{H}_{1} \mathrm{H}_{2}$ interval lengthened suddenly with resumption of the $A V$ conduction. These observations provide further evidence that the gap phenomenon has a wider spectrum than was previously thought.

There is a curious phenomenon which will be observed rarely during programmed electrical stimulation studies of the right atrium when premature stimuli are introduced. By progressively moving the stimulus earlier in the atrial cycle a point is reached when the atrial response evoked is no longer conducted to the ventricles. Rarely a still more premature atrial extrasystole than that which was blocked is paradoxically followed by a ventricular response. These are the characteristic features of the so-called gap phenomenon (Moe, Mendez, and Han, 1965; Durrer, 1968; Goldreyer and Bigger, 1969; Wit et al., 1970a; Gallagher et al., 1973a, b; Agha et al., 1973; Akhtar et al., 1974a, b; Wu et al., 1974). The explanation of it lies in the fact that the very early electrical impulse is delayed so long proximally to the original site of block that by the time it reaches that site the refractory period has been passed and conduction occurs (Wit et al., 1970a; Gallagher et al., 1973a, b). Depending on where in the proximal tissue the conduction delay takes place which allows atrioventricular conduction to be resumed, Gallagher et al. (1973a, b) distinguish arbitrarily between two types of gap. In the socalled type I the proximal region is the AV node, whereas in the type II it is the ventricular specialized conduction system.

Recently Wu et al. (1974) showed that this classification was an over simplification of the gap phenomenon and that it could also occur at other levels in the conducting system from the atria to the ventricles. The purpose of this paper is to present two cases which tend to reinforce the view of Wu et al. (1974).

Received 30 April 1975.

\section{Patients and methods}

After giving informed consent the two patients were studied in the non-sedated, post-absorptive state. Under fluoroscopic control two electrode catheters were introduced via the right femoral vein into the right heart. The first - a hexapolar catheter - was positioned against the high lateral wall of the right atrium. The distal two electrodes were used for stimulation and the next one or two for recording a uni- or bipolar high atrial electrogram. A second bipolar electrode catheter was positioned across the tricuspid valve to record the His bundle electrogram (HBE) at a filter setting of $100-270 \mathrm{cycles} / \mathrm{s}$, thus utilizing a technique slightly modified from that described by Scherlag et al. (1969). Leads I, II, III, VI, and the uni- or bipolar atrial electrogram ( $V_{\mathrm{RA}}$ or $\mathrm{B}_{\mathrm{RA}}$ respectively) were recorded simultaneously with the HBE either on an eight-channel photographic recorder (Hellige, Freiburg) or on an eight-channel directwriting recorder (Siemens, Erlangen). All recordings were taken at a paper speed of $100 \mathrm{~mm} / \mathrm{s}$. The intervals between the atrial wave of the atrial electrogram $(P)$ and the A wave of the HBE (A), the PA interval, and the A wave of the HBE and the His deflection $(H)$, the AH interval, as well as the interval between the His deflection and the ealiest time of ventricular activation on any lead (the HV interval) were measured.

The investigations were made by means of the extrastimulus method (Wit et al., 1970b). The right atrium was driven at about 5-10 beats/min faster than the sinus rhythm. The stimulation was by a specially designed pacemaker delivering premature or test stimuli $\left(\mathbf{S}_{2}\right)$ after every tenth basic driving beat $\left(S_{1}\right)$. The premature beat interval $\left(S_{1} S_{2}\right)$ was progressively shortened by 5-10 ms until the effective refractory period (ERP) of the right atrium was reached.

Case I

\section{Results}

The patient, a 67-year-old woman, gave a history of 


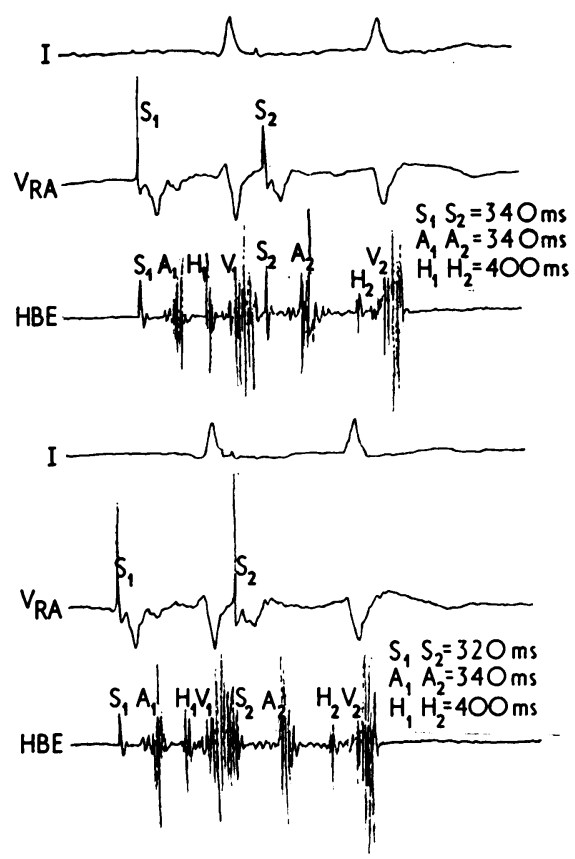

FIG. I Atrionodal gap (Case I). $V_{\mathrm{RA}}$ is a unipolar atrial lead. First and second beats in both panels were produced by the driving and testing stimuli respectively. TOP: At an $S_{1} S_{2}$ interval of $340 \mathrm{~ms} S_{2}$ is conducted to the atria without supplementary latency. воттом: At an $S_{1} S_{2}$ interval of $320 \mathrm{~ms} S_{2}$ is conducted to the atria with increasing latency, so that $S_{1} S_{2}$ interval is shorter than $A_{1} A_{2}$ interval.

dizzy spells. A His bundle study was performed to assess the functional state of the $\mathrm{AV}$ conduction system. The atria were driven at a rate of $79 / \mathrm{min}$ (cycle length $760 \mathrm{~ms}$ ). The $A_{1} A_{2}$ interval was identical to the $S_{1} S_{2}$ interval up to the premature beat interval of $330 \mathrm{~ms}$ (Fig. I). At an $S_{1} S_{2}$ interval of $320 \mathrm{~ms}$ or less the premature stimulus was conducted within the atria with progressive delay so that the $S_{1} S_{2}$ interval was increasingly shorter than the corresponding $A_{1} A_{2}$ interval (Fig. I). Thus an $S_{1} S_{2}$ interval of $280 \mathrm{~ms}$ was accompanied by an $A_{1} A_{2}$ interval of $340 \mathrm{~ms}$ and the premature atrial response was still conducted to the ventricles (Fig. 2). But a further Io ms shortening of the $S_{1} S_{2}$ interval with a corresponding $A_{1} A_{2}$ interval of $330 \mathrm{~ms}$ led to block of the premature impulse within the AV node (Fig. 2). The impulse was not conducted to the bundle of His. The effective refractory period of the AV node was thus reached. The coupling intervals $S_{1} S_{2}$ of $260 \mathrm{~ms}$ and $250 \mathrm{~ms}$ were accompanied by $A_{1} A_{2}$ intervals of $330 \mathrm{~ms}$ or less
ToP

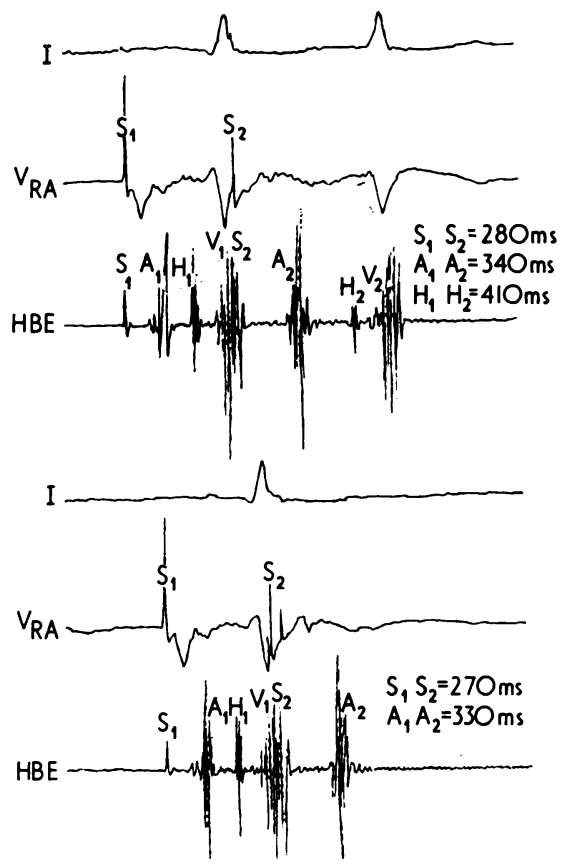

FIG. 2 Case $I$, same notation. TOP: $A V$ conduction still persists at $S_{1} S_{2}$ interval of $280 \mathrm{~ms}$. воттом: Shortening of $S_{1} S_{2}$ interval to $270 \mathrm{~ms}$ with corresponding $A_{1} A_{2}$ interval of $330 \mathrm{~ms}$. The ERP of the $A V$ node is reached and $A_{2}$ blocked above His bundle.

maintaining the $\mathrm{AV}$ block. However, at a premature beat interval of $240 \mathrm{~ms}$ or less AV conduction was resumed (Fig. 3). These coupling intervals had a corresponding $A_{1} A_{2}$ interval of $350 \mathrm{~ms}$ or more, thus exceeding the actual duration of the effective refractory period of the $\mathrm{AV}$ node. The prolongation of the $A_{1} A_{2}$ interval is explained by the delayed conduction in the atrial tissue at coupling intervals shorter than $320 \mathrm{~ms}$. At these coupling intervals the $P$ wave recorded in the unipolar atrial electrogram $\left(\mathrm{V}_{\mathrm{RA}}\right)$ appeared broad and distorted with no definite intrinsic deflection. In addition to this prolongation of the intra-atrial conduction time the latency between the stimulus artefact and the subsequent atrial wave slightly increased. The increased latency seemed to play a minor role in the prolongation of the $S_{2} A_{2}$ interval as compared to the slowed impulse propagation within the atrium itself.

The study was repeated at faster heart rates of 96 and 115 beats/min. At $A_{1} A_{2}$ intervals of 320 and $340 \mathrm{~ms}$, respectively, the effective refractory period of the AV node was reached. The premature beat was blocked above the recording site of the bundle of His. At $S_{1} S_{2}$ intervals shorter than 310 and $280 \mathrm{~ms}$ 


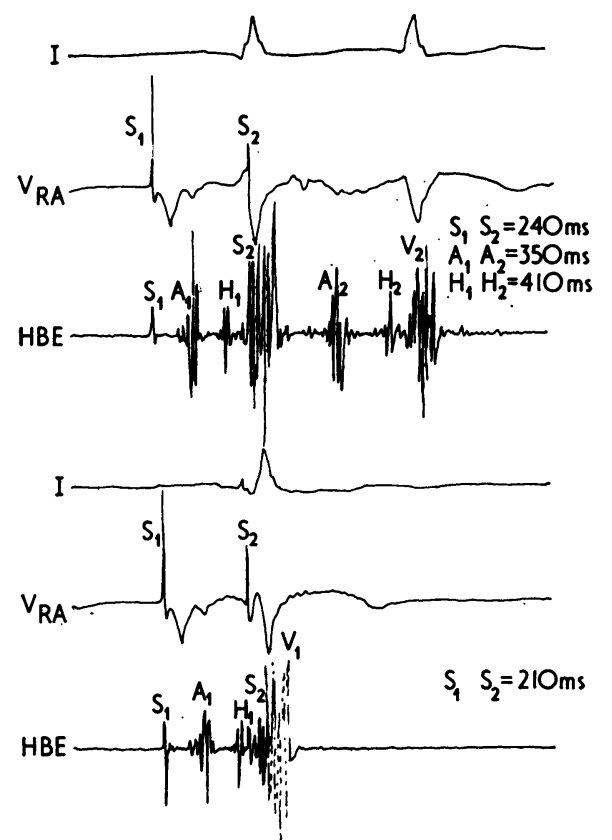

FIG. 3 Case I, same notation. TOP: Shortening of $\mathrm{S}_{1} \mathrm{~S}_{2}$ interval to $240 \mathrm{~ms}$ is followed by lengthening of $A_{1} A_{2}$ interval to $350 \mathrm{~ms}$. This value is longer than the $E R P$ of the $A V$ node and $A V$ conduction is thus resumed. воттом: At $S_{1} S_{2}$ interval of $210 \mathrm{~ms}$ the $E R P$ of the atrium is reached.

respectively the conduction delay between $S_{2}$ and $\mathrm{A}_{2}$ became gradually longer. Yet until the time of the effective refractory period of the right atrium, which was $190 \mathrm{~ms}$ for both rates, the prolongation of the $A_{1} A_{2}$ interval was not long enough to exceed the duration of the effective refractory period of the $\mathrm{AV}$ node. A gap phenomenon therefore could not ensue.

\section{Case 2}

The patient, a 42-year-old woman, had bouts of supraventricular tachycardia which were later shown to be attacks of atrial fibrillation. The atria were driven at a rate of 90 beats/min (cycle length $680 \mathrm{~ms}$ ). Until the $A_{1} A_{2}$ interval was shortened to $350 \mathrm{~ms}$, with a corresponding $\mathrm{H}_{1} \mathrm{H}_{2}$ interval of $370 \mathrm{~ms}$, the premature $\mathrm{H}_{2}$ potential was conducted to the ventricles with an $\mathrm{H}_{2} \mathrm{~V}_{2}$ interval of $35 \mathrm{~ms}$ (Fig. 4). At an $A_{1} A_{2}$ interval of $340 \mathrm{~ms}$ the $\mathrm{H}_{1} \mathrm{H}_{2}$ interval also shortened by Io $\mathrm{ms}$ (Fig. 4). $\mathrm{H}_{2}$ was now split into two distinct components $\mathrm{CH}_{2}$ and $\mathrm{H}_{2}^{\prime}$ ) with an increase of the $\mathrm{H}_{2} \mathrm{~V}_{2}$ interval to $45 \mathrm{~ms}$. A further shortening of the coupling intervals was followed by an increase of the splitting of the His potential. At the $A_{1} A_{2}$ interval of $320 \mathrm{~ms}$ with a
Top
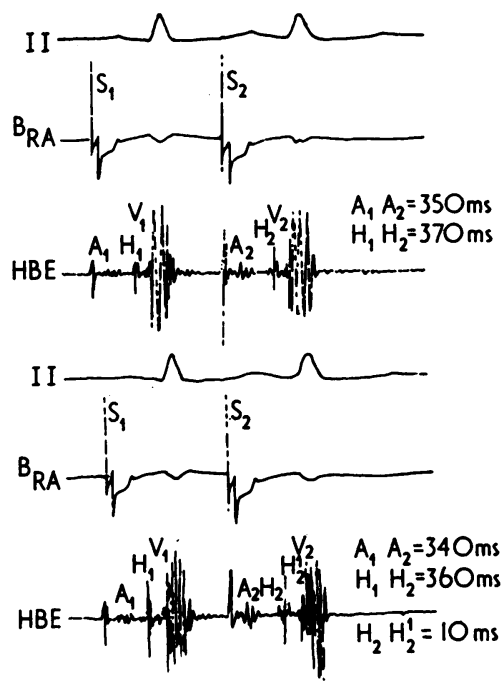

FIG. 4 Case 2. Gap at the nodo-Hisian junction. $B_{\mathrm{RA}}$ is a bipolar atrial lead. TOP: $A_{1} A_{2}$ interval of $350 \mathrm{~ms}$, with a corresponding $\mathrm{H}_{1} \mathrm{H}_{2}$ interval of $370 \mathrm{~ms}$, is accompanied by a normal configuration of the $\mathrm{H}_{2}$ potential. воттом: Shortening of $A_{1} A_{2}$ interval to $340 \mathrm{~ms}$ leads to $\mathrm{H}_{1} \mathrm{H}_{2}$ interval of $360 \mathrm{~ms}$ with splitting of the $\mathrm{H}_{2}$ potential into two distinct deflections.

Top
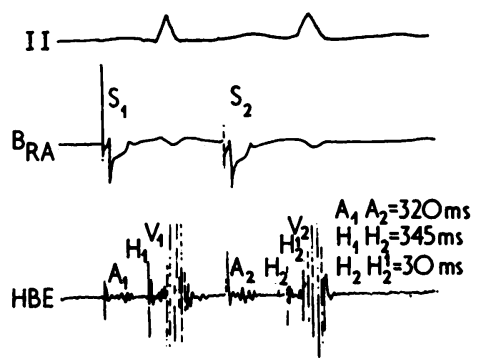

Воттом
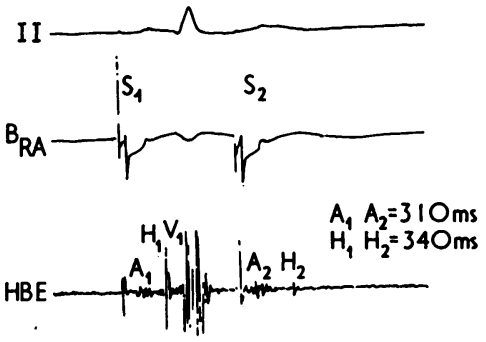

FIg. 5 Case 2, same notation. TOP: At $A_{1} A_{2}$ interval of $320 \mathrm{~ms}$ corresponding $\mathrm{H}_{1} \mathrm{H}_{2}$ interval reaches $345 \mathrm{~ms}$, whereas splitting of $\mathrm{H}_{2}$ potential increases. воттом: At $A_{1} A_{2}$ interval of $310 \mathrm{~ms}$, with corresponding $\mathrm{H}_{1} \mathrm{H}_{2}$ interval of $340 \mathrm{~ms}$, second deflection of $\mathrm{H}_{2}$ is lost, so an $\mathrm{AV}$ block ensues. 


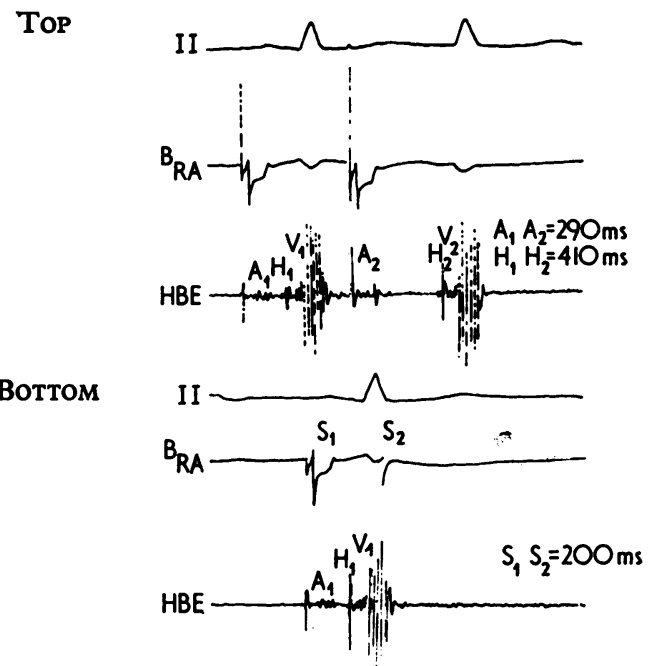

FIG. 6 Case 2, same notation. TOP: At $A_{1} A_{2}$ interval of $290 \mathrm{~ms} \mathrm{H}_{1} \mathrm{H}_{2}$ interval increases to value of $410 \mathrm{~ms}$, which restores normal $A V$ conduction. воттом: At $S_{1} S_{2}$ interval of $200 \mathrm{~ms}$ the ERP of the right atrium is reached.

corresponding $\mathrm{H}_{1} \mathrm{H}_{2}$ interval of $345 \mathrm{~ms}$ the duration between the two components of $\mathrm{H}_{2}$ reached $30 \mathrm{~ms}$ (Fig. 5). At an $\mathrm{H}_{1} \mathrm{H}_{2}$ interval of $340 \mathrm{~ms}$, produced by a shortening of the $A_{1} A_{2}$ interval to 310 and $300 \mathrm{~ms}$, only the first minor deflection of the $\mathrm{H}_{2}$ potential appeared (Fig. 5). This minor deflection could be constantly recorded after the $A_{2}$ potential.

A block between the two components of the $\mathrm{H}_{2}$ potential was thus responsible for the failure of conduction of the atrial impulse to the ventricles. At a still shorter $A_{1} A_{2}$ interval of $290 \mathrm{~ms}$ the $A_{2} H_{2}$ interval increased from 110 to $190 \mathrm{~ms}$, so that the corresponding $\mathrm{H}_{1} \mathrm{H}_{2}$ interval was now $4 \mathrm{IO} \mathrm{ms}$ (Fig. 6 (top) and Fig. 7). This was much longer than $345 \mathrm{~ms}$, at which the block between $\mathrm{H}_{2}$ and $\mathrm{H}^{\prime}{ }_{2}$ had appeared, and longer also than $360 \mathrm{~ms}$-the interval at which the fractionation of the $\mathrm{H}_{2}$ potential into two deflections occurred. Thus the corresponding $\mathrm{H}_{2}$ potential was of normal configuration and the ensuing $\mathrm{H}_{2} \mathrm{~V}_{2}$ interval of normal duration. The shortening of the $A_{1} A_{2}$ interval to 280 and $270 \mathrm{~ms}$ maintained the $\mathrm{AV}$ conduction because of an $\mathrm{H}_{1} \mathrm{H}_{2}$ interval of 410 and $420 \mathrm{~ms}$, respectively. Reducing the coupling intervals $S_{1} S_{2}$ to $260 \mathrm{~ms}$ or less led to $A_{1} A_{2}$ intervals of 270 or $280 \mathrm{~ms}$ with corresponding $\mathrm{H}_{1} \mathrm{H}_{2}$ intervals of $4 \mathrm{IO}$ and $420 \mathrm{~ms}$ respectively. This occurred because of an increasing delay between $S_{2}$ and $A_{2}$. The effective refractory period of the right atrium was reached at a $S_{1} S_{2}$ interval of $200 \mathrm{~ms}$ (Fig. 6).

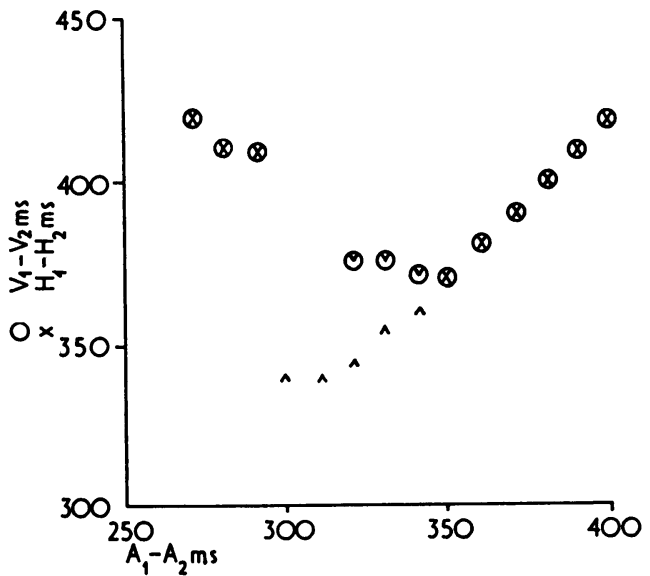

FIG. 7 Gap at nodo-Hisian junction. $A_{1} A_{2}$ interval (on abscissa) is plotted against $H_{1} H_{2}$ interval $(X)$ and the $V_{1} V_{2}$ interval $(O)$ on ordinate. At $H_{1} H_{2}$ interval of $360 \mathrm{~ms}$ splitting of the $\mathrm{H}_{2}$ potential occurs which became greater at shorter intervals. At $\mathrm{H}_{1} \mathrm{H}_{2}$ interval of 340 ms only the first $\mathrm{H}_{2}$ deflection appears. Between an $A_{1} A_{2}$ interval of 300 and $290 \mathrm{~ms}$ the $\mathrm{H}_{1} \mathrm{H}_{2}$ interval suddenly increases from 340 to $410 \mathrm{~ms}$ with disappearance of $\mathrm{H}_{2}$ splitting and of $A V$ block.

When the atria were driven at a cycle length of $500 \mathrm{~ms}$ (rate $120 / \mathrm{min}$ ) and the study repeated we were unable to reproduce the gap phenomenon. The functional refractory period (FRP) of the AV node - the shortest interval between two successive His bundle responses, both propagated from the atrium - was now at $360 \mathrm{~ms}$ but no splitting of $\mathrm{H}_{2}$ or block was observed.

\section{Discussion}

The gap phenomenon can occur when there are two regions in the chain of the impulse transmission through the heart in which the following conditions are encountered (Wit et al., 1970a; Gallagher et al., 1973a, b; Wu et al., 1974). (I) The functional refractory period of the proximal region is shorter than the effective refractory period of the distal one. This condition makes the occurrence of the block possible. (2) At shorter coupling intervals at which a block occurs a conduction delay ensues in the proximal region. Thus the impulse will be retained in this region so long that the distal one regains its excitability and restores the conduction to the ventricles. This explains the disappearance of the block at shorter coupling intervals.

A distinction has been made between type $I$ and type II gap phenomena based on the localization of the proximal region of conduction delay (Galla- 
gher et al., 1975a, b; Agha et al., 1973). In the type I gap it is the AV node, whereas in the type II gap the conduction delay is in the ventricular specialized conduction system. In both types of gap the distal region of block is in the ventricular specialized conduction system.

As Wu et al. (1974) showed, there are other possible sites of conduction delay in addition to the AV node (as in type I) and the ventricular specialized conduction system (as in type II). They are in the atrium and in the bundle of His itself. Wu et al. described a case in which the gap occurred between the His bundle as the proximal region and the ventricular specialized conduction system or a bundle-branch as the distal region. They therefore proposed that the previous classification should be replaced by one based on the proximal and distal regions involved in the gap phenomenon. Our first case is an example of a gap between the right atrium as the proximal region and the AV node as the distal region. Similar cases have been described not only by Wu et al. (1974) but also by Narula (1973), who named it 'pseudo-supernormal AV conduction.'

Neuss and Schlepper (1973) described a patient with WPW syndrome type A. At a given coupling interval during atrial stimulation the effective refractory period of the accessory pathway was reached and the conduction to the ventricles followed only through the AV node-His system. At shorter coupling intervals the intra-atrial conduction time was so prolonged that the impulse reached the accessory pathway out of the refractory period and the WPW pattern reappeared. This last case represents, in fact, a particular form of gap with the right atrium as the proximal region and the accessory pathway as the distal region.

Our second case is similar to Case 3 of Wu et al. (1974), in which there was a gap between the AV node and the His bundle. In contrast to our case the site of the block in their case was distal to the recording site of the second component of $\mathrm{H}_{2}$. Our case is unique in that the block occurred between the two deflections of the split $\mathrm{H}$ potential. The validity of a split $\mathrm{H}$ potential has been proved by means of simultaneous recordings of trans-membrane potential and a bipolar extracellular electrogram (Varghese et al., 1973). The study showed a good correlation between the two forms of recording.

Most authors agree that splitting of the $H$ potential represents a first degree intra-Hisian block (Narula et al., 1971; Peuch et al., 1972; El-Sherif et al., 1974; Fleischmann and Pop, 1975). A second degree intra-Hisian block appears as an intermittent loss of the second component sometimes preceded by a prolongation of the interval between the two components (Narula et al., I97I; Peuch et al., 1972). If the first component is too small to be recorded the block can be wrongly interpreted as occurring in the AV node and not in the His bundle. This was reported by El-Sherif et al. (1974). We think that if the recording catheter had been advanced a few millimetres into the right ventricle the first component of $\mathrm{H}_{2}$ would have been lost and a nodal site of block would be postulated. Therefore a distinction between a nodal and a Hisian block will sometimes be difficult to make.

The resumption of AV conduction was accomplished in our second case by a sudden increase in the AH interval. Though the sudden increase of the AV nodal time may be interpreted as a manifestation of longitudinal AV nodal dissociation (Denes et al., 1973; Denes, Wu, and Rosen, 1974) echo beats or bouts of supraventricular re-entrant tachycardia did not occur in our patient.

The effect of the driving rate on the occurrence of the gap phenomenon has been emphasized by Wit et al. (1970a). They showed that a gap between the AV node as the proximal region and the ventricular specialized conduction system as the distal region occurred more often at lower rates. This is explained by the influence of the driving rate on the refractory periods of the tissues involved. At lower rates the effective refractory period of the ventricular specialized conduction system is increased while the functional refractory period of the AV node will be shortened or sometimes lengthened. If there is a shortening of the functional refractory period of the $A V$ node associated with a lengthening of the effective refractory period of the ventricular specialized conduction system a gap phenomenon occurs more easily with the lower rate. The same is true for the gap at the nodo-Hisian junction, and explains why in our second case the gap phenomenon was observed at a lower but not at a higher rate.

In our first patient also the gap occurred only at lower rates. Wu et al. (1974) predicted that a gap between the atria and the AV node would occur more easily at higher rates. Shorter cycle lengths tend to shorten the effective refractory period of the atrium and lengthen the effective refractory period of the AV node (Wit et al., 1970a) and AV block will occur more easily. Yet, despite the opposing effects on the effective refractory periods of the atrium and the AV node, the increase in conduction delay at shorter coupling intervals between the test stimulus and the atrial deflection in the His bundle electrogram will not always be long enough to allow the passage of the impulse over the AV node to return. 


\section{References}

Agha, A. S., Castellanos, A., Wells, D., Ross, M. D., Befeler, B., and Myerburg, R. J. (1973). Type I, Type II, and Type III gaps in bundle-branch conduction. Circulation, $47,325$.

Akhtar, M., Damato, A. N., Batsford, W. P., Caracta, A. R., Vargas, G., and Lau, S. H. (1974a). Unmasking and conversion of gap phenomenon in the human heart. Circulation, 49, 624 .

Akhtar, M., Damato, A. N., Caracta, A. R., Batsford, W. P., Josephson, M. A., and Lau, S. H. (1974b). Electrophysiologic effects of atropine on atrioventricular conduction studied by His bundle electrogram. American fournal of Cardiology, 33, 333.

Bharati, S., Lev, M., Wu, D., Denes, P., and Rosen, K. M. (1974). Pathophysiologic correlations in two cases of split His-bundle potentials. Circulation, 49, 615.

Denes, P., Wu, D., Dhingra, R. C., Chuquimia, R., and Rosen, K. M. (1973). Demonstration of dual A-V nodal pathways in patients with paroxysmal supraventricular tachycardia. Circulation, 48, 549.

Denes, P., Wu, D., and Rosen, K. M. (1974). Demonstration of dual A-V pathways in a patient with Lown-GanongLevine syndrome. Chest, 65, 343.

Durrer, D. (1968). Electrical aspects of human cardiac activity. A clinical-physiological approach to excitation and stimulation. Cardiovascular Research, 2, I.

El-Sherif, N., Scherlag, B. J., Lazzara, R., Hope, R., Williams, D. O., and Samet, P. (1974). The pathophysiology of tachycardia-dependent paroxysmal atrioventricular block after acute myocardial ischemia: experimental and clinical observations. Circulation, 50, 515.

Fleischmann, D., Mathey, D., Bleifeld, W., Irnich, W., and Effert, S., (1973). His-Bundel-Elektrographie bei Patienten mit intraventrikulären Leitungsstörungen. Klinische Wochenschrift, 51, 1066.

Fleischmann, D., and Pop, T. (1976). Nachweis von Reizleitungsstörungen im Bündel mittels intrakardialer Ableitung. Zeitschrift für Kardiologie. In preparation.

Gallagher, J. J., Damato, A. N., Caracta, A. R., Varghese, P. J., Josephson, M. E., and Lau, S. H. (1973a). Gap in A-V conduction in man: types I and II. American Heart fournal, 85, 78.

Gallagher, J. J., Damato, A. N., Varghese, P. J., Caracta, A. R., Josephson, M. E., and Lau, S. H. (1973b). Gap in A-V conduction in man. Type I and Type II. Clinical Research, 20, 373.

Goldreyer, B. N., and Bigger, J. T. (1969). Spontaneous and induced reentrant tachycardia. Annals of Internal Medicine, 70, 87.

Moe, G. K., Mendez, C., and Han, J. (1965). Aberrant A-V impulse propagation in the dog heart. A study of functional bundle branch block. Circulation Research, 16, 261 .

Narula, O. S. (1973). Conduction disorders in the AV transmission system. In Cardiac Arrhythmias, p. 259. Ed. by L. S. Dreifus and W. Likoff. Grune and Stratton, New York and London.

Narula, O. S., Scherlag, B. J., Samet, P., and Javier, R. P. (I97I). Atrioventricular block: localization and classification by His bundle recordings. American fournal of Medicine, 50, 146.

Neuss, H., and Schlepper, M. (1973). Befunde zur supernormalen atrio-ventrikulären Erregungsleitung. Zeitschrift für Kardiologie, 62, 267.

Peuch, P., Grolleau-Raoux, R., Latour, H., Cabasson, J., Robin, J. M., Baissus, C., and Gilbert, M. (1972). Diagnostic des blocs tronculairs hisiens par l'enregistrement endocavitaire et la stimulation du faisceau de His. Archives des Maladies du Cour et des Vaisseaux, 65, 315.

Scherlag, B. J., Lau, S. H., Helfant, R. H., Berkowitz, W. D., Stein, E., and Damato, A. N. (1969). Catheter technique for recording His bundle activity in man. Circulation, 39, 13.

Varghese, P. J., Elizari, M. V., Lau, S. H., and Damato, A. N. (1973). His bundle electrograms of dog. Correlation with intracellular recordings. Circulation, 48, 753.

Wit, A. L., Damato, A. N., Weiss, M. B., and Steiner, C. (1970a). Phenomenon of the gap in atrioventricular conduction in the human heart. Circulation Research, 27, 679.

Wit, A. L., Weiss, M. B., Berkowitz, W. D., Rosen, K. M., Steiner, C., and Damato, A. N. (1970b). Patterns of atrioventricular conduction in the human heart. Circulation Research, 27, 345.

Wu, D., Denes, P., Dhingra, R., and Rosen, K. M. (1974). Nature of the gap phenomenon in man. Circulation Research, 34, 682.

Requests for reprints to Dr. T. Pop, First Medical Div1sion, Rheinisch-Westfälische Technische, Hochschule Aachen, 5 I Aachen, Goethester. 27, West Germany. 